\title{
Inquisição e sociedade a formação da rede de familiares do Santo Ofício em Minas Gerais colonial (1711-1808)*
}

\author{
Inquisition and society \\ the creation of the network of "familiares" in \\ colonial Minas Gerais captaincy - Brazil (1711-1808)
}

\author{
ALDAIR CARLOS RODRIGUES"* \\ Doutorando em História Social na USP \\ Departamento de História/FFLCH/USP \\ Av. Prof. Lineu Prestes 338 \\ 05508-900 São Paulo SP \\ aldairr@yahoo.com.br
}

\begin{abstract}
RESUMO Este trabalho investiga o processo de formação da rede de familiares do Santo da capitania de Minas Gerais durante o século XVIII. A análise, com enfoque no aspecto social da familiatura, leva em conta, por um lado, o contexto externo, ou seja, a expedição de cartas de familiares para Minas em comparação com outras áreas sob jurisdição da Inquisição portuguesa; e, por outro, explica o fenômeno a partir do contexto interno. Aqui, buscamos compreender a formação da rede em sua relação com o processo de formação social e econômica da Capitania, destacando a distribuição das familiaturas por comarcas e períodos.
\end{abstract}

Palavras-chave familiares do Santo Ofício, Minas Gerais colonial, Inquisição

\footnotetext{
* Artigo recebido em 17/11/2008. Aprovado em 16/092009.

** Bolsista FAPESP. Graduado em História pela UFOP, Mestre em História Social pela USP. Pesquisa realizada com o apoio da FAPESP (Fundação de Amparo à Pesquisa do Estado de São Paulo), Instituto Cultural Amílcar Martins, Cátedra Jaime Cortesão da FFLCH-USP e Instituto Camões.
} 
ABSTRACT This paper investigates the process of creating a network of the Inquisition's familiares (non religious representatives of the Inquisition) in Minas Gerais captaincy/Brazil, during the Eighteenth century. The analysis focuses on the social side of this network, examining the number of the documents investing the representatives in Minas in comparison with other areas under the jurisdiction of the Portuguese Inquisition and how the internal characteristics of the captaincy influenced it. We also aim to understand the social and economic background of this network in the captaincy society, highlighting the distribution of members by inner regions and periods.

Keywords Holly Office, Minas Gerais captaincy, Inquisition.

De acordo com os regimentos inquisitoriais, os familiares exerceriam um papel auxiliar nas atividades da Inquisição, atuando principalmente nos seqüestros de bens, notificações, prisões e condução de réus. Sem abandonar suas ocupações costumeiras, eles seriam funcionários civis do Santo Ofício e, caso fossem chamados pelos inquisidores - nos locais onde o tribunal havia se instalado - ou pelos comissários, prestariam a estes últimos todo o auxílio requerido e cumpririam as ordens que Ihes fossem emitidas. ${ }^{1}$

Para se habilitar como familiar, o candidato devia ser abastado de bens, "viver limpamente", não ter ascendente condenado pelo Santo Ofício e principalmente "ser limpo de sangue". Os descendentes de judeus, mouros, mulatos não eram aceitos no quadro de agentes inquisitoriais. ${ }^{2}$ A distinção social oferecida pela familiatura estava ligada à perpetuação, através dos estatutos de limpeza de sangue, da fratura da ordem social portuguesa que separava, do lado positivo, os limpos de sangue (cristãos-velhos) e, do lado negativo, os de "sangue infecto" (sobretudo os descendentes de judeus). Nesta perspectiva, a familiatura funcionava como um atestado público de limpeza de sangue.

Feitas estas considerações, nas linhas abaixo, o nosso objetivo é verificar como ocorreu o processo de formação da rede de familiares da

1 Sobre a atuação dos familiares, Cf. CALAINHO, Daniela Buono. Em nome do Santo Ofício: familiares da Inquisição portuguesa no Brasil colonial. Rio de Janeiro: UFRJ, 1992. (História, Dissertação de Mestrado). Publicada como CALAINHO, Daniela Buono. Agentes da fé: familiares da Inquisição portuguesa no Brasil colonial. Bauru: EDUSC, 2006; RODRIGUES, Aldair Carlos. Sociedade e Inquisição em Minas colonial: os familiares do Santo Ofício (17111808). São Paulo: FFLCH-USP, 2007, p.53-79. (História, Dissertação de Mestrado).

2 Apesar de ser reputada como a mais rigorosa na aplicação dos estatutos de limpeza de sangue, a Inquisição não era a única instituição do Antigo Regime que adotava esse critério para a admissão de alguém em seus quadros. Sobre esta questão e sobre a implantação dos estatutos de limpeza de sangue em Portugal, de modo geral, ver: OLIVAL, Fernanda. Rigor e interesses: os estatutos de limpeza de sangue em Portugal. Cadernos de Estudos Sefarditas, n.4, p.151-182, 2004. Sobre uma análise detida do processo de habilitação ao cargo de familiar, ver RODRIGUES, Aldair Carlos. Sociedade e Inquisição em Minas colonial: os familiares do Santo Ofício (1711-1808). São Paulo: FFLCH-USP, 2007, p.80-114. (História, Dissertação de Mestrado). 
capitania de Minas Gerais, considerando, sobretudo as variantes espaço e tempo. Primeiramente, a análise terá em conta o contexto externo, ou seja, a expedição de familiaturas para Minas em comparação às outras áreas sob jurisdição da Inquisição portuguesa. Em seguida, reduziremos a escala de observação - destacando a distribuição das patentes por comarca e período - e analisaremos o fenômeno à luz do processo de formação social e econômica da Capitania.

Comecemos a análise observando as curvas que demonstram o ritmo de expedição de familiaturas pela Inquisição portuguesa. Considerando intervalos de 50 anos, observamos que, no período que vai de 1671 a 1720, a quantidade de familiaturas expedidas pelo Santo Ofício aumentou de 2.285 - referente ao meio século anterior (1621-1670) - para 6.488. Depois desse grande salto, assistimos, no intervalo que vai de 1721 a 1770, ao auge da expedição de familiaturas, que atinge 8.680 familiares habilitados. Depois de chegar ao seu pico, o meio século subseqüente, 1771-1820, apresenta uma queda brusca no número de habilitações de familiares, passando de 8.680 para 2.746 familiaturas. ${ }^{3}$ Tal fenômeno está relacionado à decadência da Inquisição sob o Reformismo llustrado, sobretudo no que se refere à abolição da distinção entre cristãos-velhos e cristãos-novos. Em poucas palavras, Pombal domesticou a Inquisição. ${ }^{4} \mathrm{~A}$ distinção social oferecida pela familiatura estava ligada ao atestado de limpeza de sangue que ela representava. Depois que Pombal abole, ao nível institucional, essa distinção, a capacidade de intervenção do Santo Ofício nesse campo fica debilitada e a familiatura perde muito de seu capital simbólico.

Quadro 1: Familiares do Santo Ofício Habilitados pela Inquisição portuguesa (por blocos de meio século)

\begin{tabular}{|c|c|}
\hline Blocos de meio século & Número de Habilitações \\
\hline $1570-1620$ & 702 \\
\hline $1621-1670$ & 2285 \\
\hline $1671-1720$ & 6488 \\
\hline $1721-1770$ & 8680 \\
\hline $1771-1820$ & 2746 \\
\hline
\end{tabular}

Fonte: TORRES, José Veiga. Da repressão religiosa para a promoção social: a Inquisição como instância legitimadora da promoção social da burguesia mercantil, p.127.

3 Todos estes dados em: TORRES, José Veiga. Da repressão religiosa para a promoção social: a Inquisição como instância legitimadora da promoção social da burguesia mercantil. Revista Crítica de Ciências Sociais, n.40, p.109135, out.1994

4 MAXWELL, Kenneth. Marquês de Pombal: paradoxo do lluminismo. 2a .ed. Rio de Janeiro: Paz e Terra, 1997, p 95117. Sobre o Reformismo llustrado português, ver também VILLALTA, Luiz Carlos. Reformismo ilustrado, censura e práticas de leitura: usos do livro na América portuguesa. São Paulo: USP, 1999, p.135-176. (História, Tese de doutoramento). 
Gráfico 1: Familiares do Santo Ofício Habilitados pela Inquisição portuguesa

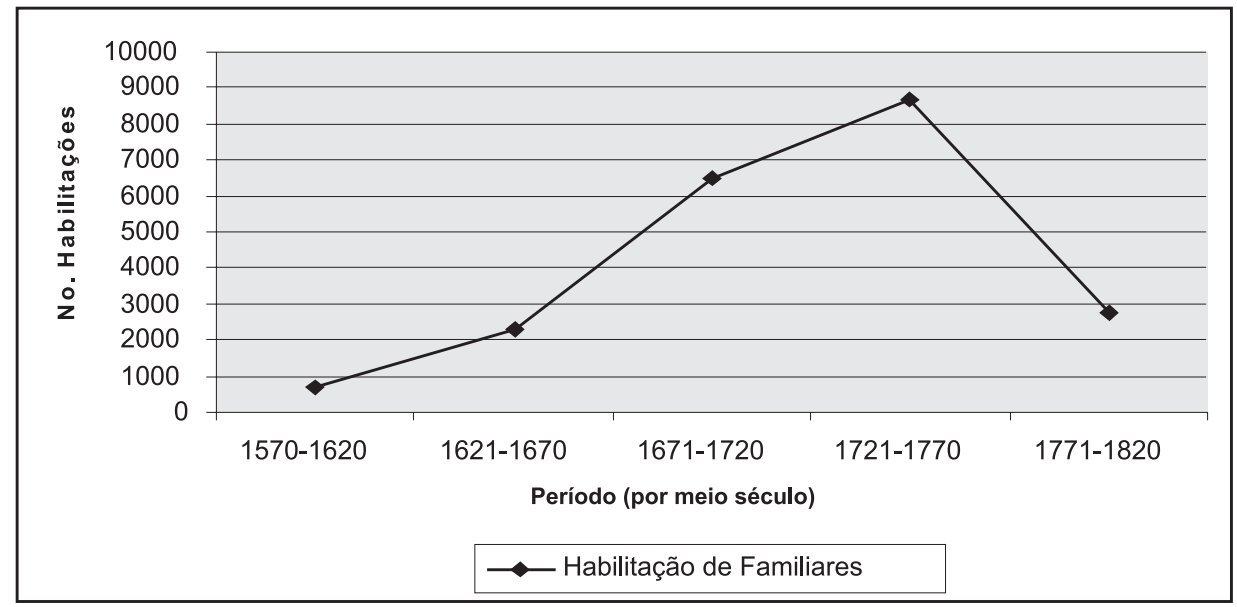

Fonte: TORRES, José Veiga. Da repressão religiosa para a promoção social, p.127.

Distribuindo o número de habilitações de familiares em intervalos de 10 anos e comparando-o com a cifra de sentenciados pela Inquisição no mesmo período (Gráfico 2), Veiga Torres observou "um movimento global simétrico, mas de sentido invertido". ${ }^{5}$ Até a década 1681-1690, o número de sentenciados sempre foi maior que o número de familiaturas expedidas. Nos dois decênios seguintes, ou seja, 1691-1700 e 1701-1710, o número de cartas de familiares expedidas pela Inquisição ultrapassou o de sentenciados, o que começa a indicar uma inversão da lógica repressiva inquisitorial. Entretanto, nos decênios subseqüentes, de 1711 a 1730, o número de sentenciados voltou a superar a cifra de familiaturas expedidas. Essas duas últimas décadas, quando situadas no contexto geral da criação de familiares, aparecem como uma exceção da tendência geral de inflação do número de familiaturas. A partir da década 1731-1740, a curva da expedição de cartas de familiar volta a se sobrepor à dos sentenciados, e daí em diante a curva da repressão nunca mais alcançaria a da expedição de cartas de familiaturas. ${ }^{6}$

Ao se levar em conta o comportamento das curvas de expedição de familiaturas e analisando o perfil dos que se habilitavam como familiar, geralmente ligados à atividade comercial, Veiga Torres pôde afirmar, com algum exagero, que "desde o último quartel do século XVII, a principal atividade da Inquisição desenvolver-se-á mais em ordem de promoção social, do

5 TORRES, José Veiga. Da repressão religiosa para a promoção social: a Inquisição como instância legitimadora, p.129

6 TORRES, José Veiga. Da repressão religiosa para a promoção social: a Inquisição como instância legitimadora, p.127. 
que ao seu controle pela repressão". ${ }^{7}$ Na perspectiva do autor, a Inquisição criava familiares não mais para atender às necessidades repressivas do Tribunal, mas sim para atender à pressão por legitimação social que o título de familiar oferecia.

\section{Gráfico 2: Relação sentenciados/ familiares (por decênios)}

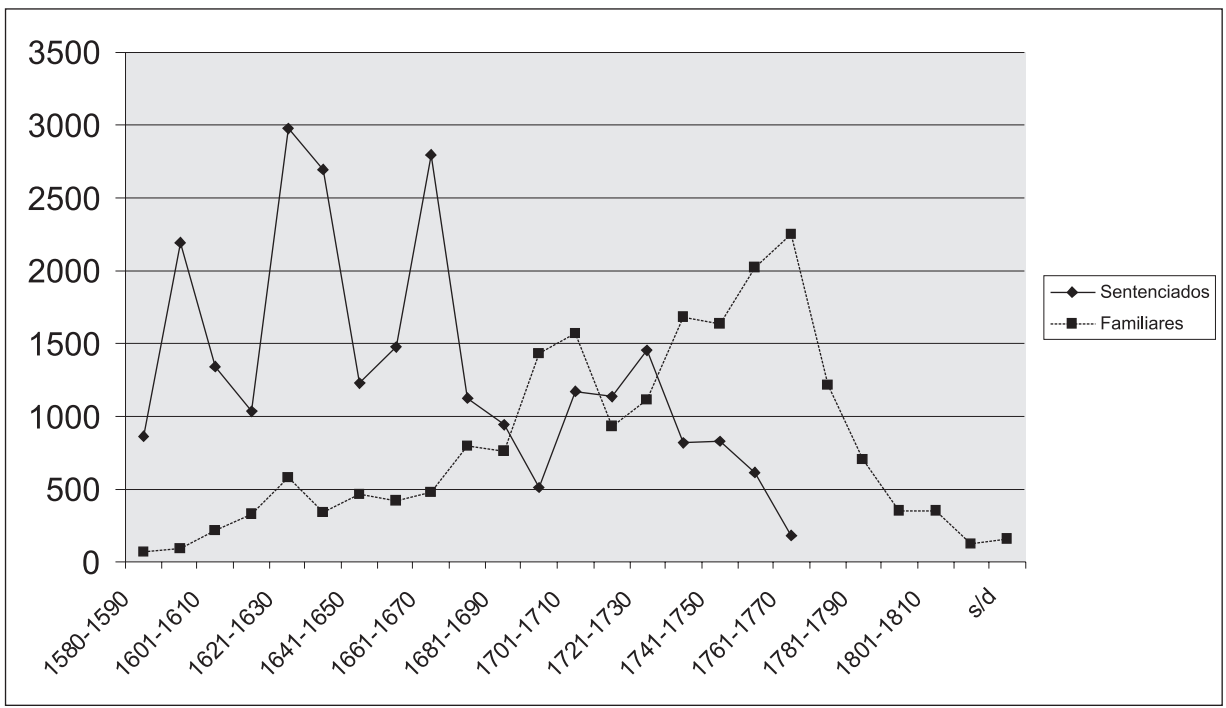

Fonte: TORRES, José Veiga. Da repressão religiosa para a promoção social: a Inquisição como instância legitimadora da promoção social da burguesia mercantil, p.129.

Apesar de indubitavelmente a familiatura ter se voltado mais para uma função social, ou seja, oferecendo prestígio e distinção social, sobretudo a partir de finais do século XVII e até o terceiro quartel do século XVIII, não podemos esquecer que os familiares do Santo Ofício eram agentes da Inquisição e, enquanto tais, cumpriam uma série de funções. Por não utilizar a documentação inquisitorial resultante diretamente da ação repressiva do Santo Ofício, Veiga Torres subestimou as funções institucionais dos familiares. Em pesquisa realizada nos cadernos do promotor, registros de correspondências e processos de réus da Inquisição de Lisboa, pudemos encontrar vários episódios em que os familiares de Minas Gerais (e também de outras regiões), aparecem desempenhando uma série de funções enquanto agentes inquisitoriais, funcionando eles, dessa forma, como uma ramificação capilar do tribunal lisboeta. ${ }^{8}$

7 TORRES, José Veiga. Da repressão religiosa para a promoção social: a Inquisição como instância legitimadora p.113.

8 Sobre esta questão, ver RODRIGUES, Aldair Carlos. Sociedade e Inquisição em Minas colonial: os familiares do Santo Ofício, p.53-79. James Wadsworth, por também não utilizar em seu trabalho a documentação resultante das atividades repressivas do Santo Ofício - ou seja, concentrou-se nas habilitações e provisões -, seguiu na mesma 
No entanto, apesar dos familiares cumprirem uma série de funções enquanto peças do aparelho inquisitorial, não eram tais necessidades institucionais que ditavam o ritmo da expedição das cartas de familiares. A Inquisição expedia as familiaturas mais de acordo com a procura pelo título. Portanto, é predominantemente o aspecto social que explica o comportamento das curvas de expedição de familiaturas, pelo menos no século $\mathrm{XVIII.}{ }^{9}$ Contudo, acreditamos que este fenômeno não eliminava as atividades repressivas e de controle social exercidas pelo Santo Ofício a partir do final do século XVII e ao longo da centúria seguinte.

O ritmo das habilitações de familiares do Santo Ofício no Brasil colonial que ficava sob jurisdição do Tribunal de Lisboa - seguiu a mesma tendência de inflação que observamos no contexto geral da Inquisição portuguesa. 0 número de familiaturas expedidas para a América portuguesa começa a ganhar fôlego no final do século XVII e atinge o seu ápice entre 1721 e 1770. No último período de atividade da Inquisição, notamos um declínio absoluto da expedição de familiaturas, nada mais do que um sintoma da decadência do tribunal.

Comparando a curva de expedição de cartas de familiar para o Brasil e para Lisboa, percebemos que, apesar de ocorrer, no último meio século de atividade inquisitorial, uma queda drástica em ambas as curvas, a do Brasil caiu um pouco menos: de 1.687 para 872, enquanto que a queda do número de familiaturas expedidas para Lisboa diminui de 2.680 para 363. Portanto, a decadência da Inquisição, os ventos da llustração e o impacto da abolição da distinção entre cristãos-novos e cristãos-velhos foi ligeiramente menos sentida na periferia. Na metrópole era mais fácil perceber a decadência do Santo Ofício, e, em conseqüência disso, lá o desinteresse pelo título de familiar ocorreu de forma mais drástica.

Quadro 2: Familiaturas expedidas para o Brasil e Lisboa

\begin{tabular}{|c|c|c|c|}
\hline Período & Brasil & Lisboa & Total \\
\hline $1570-1620$ & 4 & 200 & 702 \\
\hline $1621-1670$ & 25 & 821 & 2.285 \\
\hline $1671-1720$ & 526 & 1.647 & 5.488 \\
\hline $1721-1770$ & 1.687 & 2.680 & 8.680 \\
\hline $1771-1820$ & 872 & 363 & 2.746 \\
\hline Total Geral & 3.114 & 5.711 & 19.901 \\
\hline
\end{tabular}

Fonte: TORRES, José Veiga. Da repressão religiosa para a promoção social: a Inquisição como instância legitimadora da promoção social da burguesia mercantil, p.134.

esteira de Veiga Torres e subestimou as atividades institucionais dos familiares. WADSWORTH, James. Agents of orthodoxy: inquisitional power and prestige in colonial Pernambuco, Brazil. Arizona: University of Arizona, 2002 (História, Tese de doutoramento.) Publicada como WADSWORTH, James. Agents of orthodoxy: honor, status, and the Inquisition in colonial Pernambuco, Brazil. Boulder (CO): Rowman \& Littlefield, 2006.

9 Bethencourt aponta que, ao atender a demanda por distinção social através da familiatura, a Inquisição ampliava sua base de apoio entre as novas elites. BETHENCOURT, Francisco. História das Inquisições. São Paulo: Companhia das Letras, 2000, p.51-66. 
Gráfico 3: Familiaturas expedidas para o Brasil e Lisboa

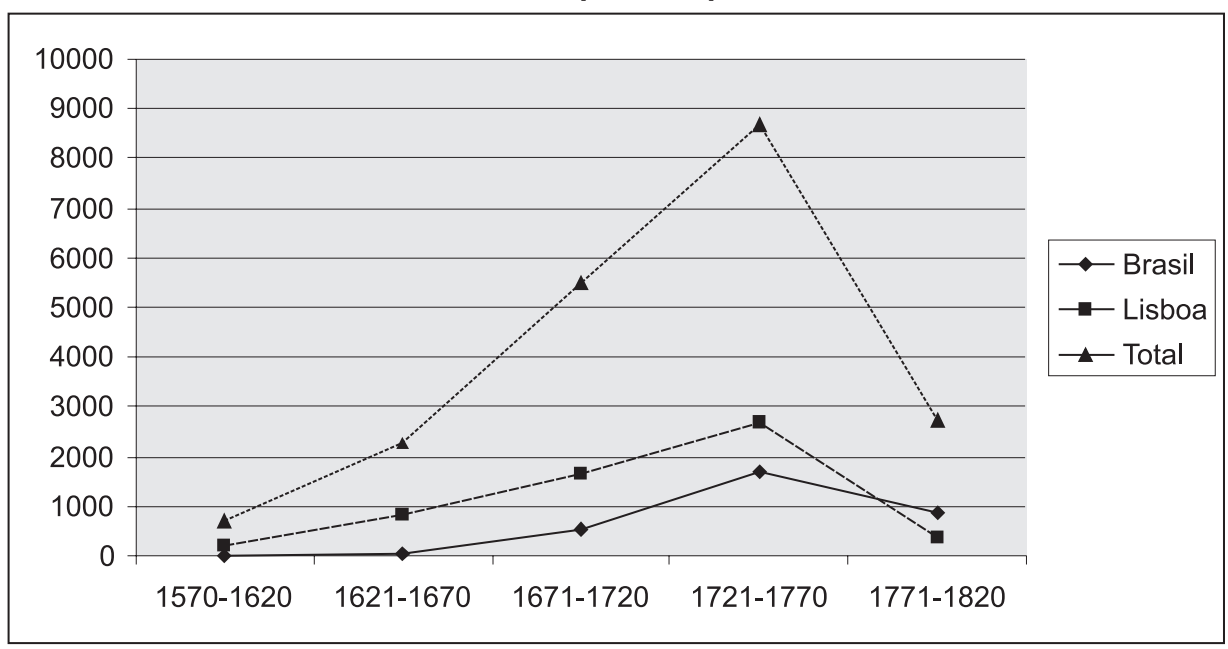

Fonte: TORRES, José Veiga. Da repressão religiosa para a promoção social: a Inquisição como instância legitimadora da promoção social da burguesia mercantil, p 134.

As familiaturas expedidas para a colônia, ao longo do século XVIII, tenderam a se concentrar nas capitanias da Bahia, Pernambuco, Rio de Janeiro e Minas Gerais. A rede de agentes inquisitoriais leigos das outras capitanias era pouco expressiva: apenas São Paulo e Pará chegaram a ter algumas dezenas de familiares, porém não era nada que se comparasse às redes com centenas de agentes existentes para as primeiras capitanias citadas (Quadro 3). Para o período abarcado por este levantamento 1713-1785 - , ${ }^{10}$ em números absolutos, a capitania do Rio de Janeiro foi a que contou com a maior rede de familiares do Santo Ofício, que atinge 529 agentes; seguida pela da Bahia, com 460 agentes; de Minas Gerais, com 447 familiares e Pernambuco, com 318 oficiais.

10 O levantamento da expedição das cartas de familiares para toda a América portuguesa, foi realizado a partir dos livros de registros de provisões da Inquisição de Lisboa, e abrange o período que vai de 1713 a 1785. 
Quadro 3: Total'11 de familiares habilitados no Brasil no século XVIII (1713-1785)

\begin{tabular}{|c|c|c|c|c|c|c|c|c|c|c|c|c|c|c|c|c|}
\hline ๙ீ & $\underset{\leftarrow}{\stackrel{\sim}{\tau}}$ & $\begin{array}{l}\hat{\omega} \\
\tilde{m}\end{array}$ & $\begin{array}{l}\text { o } \\
\sim\end{array}$ & $\stackrel{\sim}{\underset{\sigma}{\sim}}$ & $\begin{array}{l}\infty \\
0 \\
0\end{array}$ & م & $\begin{array}{l}\widetilde{0} \\
0 \\
0\end{array}$ & $\stackrel{\infty}{\circ}$ & $\begin{array}{l}\text { ठ } \\
\simeq\end{array}$ & $\begin{array}{l}\widetilde{O} \\
\text { on }\end{array}$ & $\begin{array}{l}\infty \\
\infty \\
\infty\end{array}$ & $\frac{F}{\tilde{m}}$ & $\stackrel{\text { లి }}{\sim}$ & \begin{tabular}{l}
$\infty$ \\
$\stackrel{\infty}{\sigma}$ \\
\multirow{\sigma}{*}{}
\end{tabular} & $\begin{array}{l}\infty \\
\text { on } \\
15\end{array}$ & 으 \\
\hline $\begin{array}{l}\overline{\widetilde{\pi}} \\
\text { 互 }\end{array}$ & 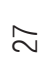 & $\infty$ & F & $\Phi$ & $\stackrel{\varrho}{=}$ & ఠิ & 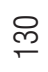 & $\stackrel{\llcorner}{\sim}$ & 㐫 & $\stackrel{尺}{\approx}$ & $\stackrel{\infty}{\infty}$ & 怘 & $\underset{\square}{\check{\Xi}}$ & ஜூ & $\underset{\Xi}{\Xi}$ & 요 \\
\hline$\stackrel{\Upsilon}{\alpha}$ & 0 & 0 & 0 & 0 & 0 & 0 & 0 & 0 & 0 & 0 & 0 & 0 & - & 0 & 0 & - \\
\hline 山 & 0 & 0 & 0 & 0 & 0 & 0 & 0 & 0 & $\leftarrow$ & 0 & 0 & 0 & 0 & 0 & 0 & $\leftarrow$ \\
\hline 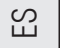 & 0 & 0 & 0 & 0 & 0 & 0 & 0 & 0 & $m$ & - & 0 & 0 & - & 0 & 0 & ما \\
\hline$\stackrel{\models}{\Sigma}$ & 0 & 0 & 0 & 0 & 0 & 0 & - & $\leftarrow$ & 0 & 0 & $\leftarrow$ & 0 & $m$ & 0 & - & $\sim$ \\
\hline$\vec{\alpha}$ & 0 & - & 0 & 0 & 0 & 0 & 0 & 0 & 0 & 0 & 0 & - & 0 & 0 & 0 & $\sim$ \\
\hline $\mathbb{a}$ & 0 & - & 0 & 0 & 0 & $\nabla$ & $\wedge$ & $m$ & $\sim$ & - & 0 & $\nabla$ & $\sim$ & 0 & - & $\bar{m}$ \\
\hline $\bar{\alpha}$ & - & 0 & 0 & 0 & 0 & 0 & 0 & 0 & 0 & 0 & 0 & - & 0 & 0 & 0 & $\sim$ \\
\hline 山 & $m$ & 0 & 0 & 0 & 0 & 0 & 0 & 0 & 0 & 0 & - & 0 & $\tau$ & 0 & 0 & ما \\
\hline के & - & $m$ & 0 & $\sim$ & 0 & $\sim$ & $m$ & مـ & $\sigma$ & ما & - & $\sim$ & - & 0 & - & $\subsetneq$ \\
\hline ฉ & $\stackrel{ }{ }$ & $\hat{=}$ & $\stackrel{\bullet}{\bullet}$ & প্ & $\stackrel{\sim}{\sim}$ & ח & 요 & $\approx$ & R & $\hat{L}$ & 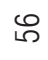 & $\infty$ & $\lesssim$ & م & $\sim$ & న్ర \\
\hline$\cong$ & 0 & $\sim$ & 0 & 0 & $m$ & 0 & $\sim$ & 0 & $\leftarrow$ & 0 & $\sim$ & 0 & $\sim$ & 0 & $\sim$ & $\stackrel{\nabla}{\ulcorner}$ \\
\hline ш & - & مـا & $m$ & 0 & 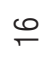 & 0 & 0 & $\infty$ & $\cong$ & $\neq$ & 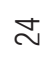 & Бs & Ұ & in & 도 & $\frac{\infty}{m}$ \\
\hline O & 0 & $\nabla$ & $\nabla$ & $\stackrel{\infty}{\infty}$ & $\bar{\sim}$ & ని & $\mathcal{Y}$ & $\bar{\sigma}$ & ๙ & $\mathscr{0}$ & న్ల & \& & ని & $\mp$ & (1) & F \\
\hline$\sum$ & 0 & 0 & 0 & 0 & 0 & 0 & 0 & 0 & 0 & $\sim$ & - & 0 & - & $\sim$ & 0 & 0 \\
\hline 유 & 0 & 0 & 0 & 0 & 0 & 0 & - & 0 & - & - & $m$ & $m$ & - & $m$ & 0 & $\stackrel{m}{\square}$ \\
\hline 心 & 0 & 0 & 0 & 0 & 0 & $\sim$ & - & 0 & $\nabla$ & $\lambda$ & - & - & $\sim$ & - & 0 & 으 \\
\hline ๘ & $\mp$ & 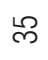 & $\underset{\sim}{ذ}$ & $\stackrel{\sim}{\sim}$ & $\stackrel{\varphi}{\square}$ & $m$ & $\underset{\sim}{\sim}$ & $\stackrel{\sim}{\sim}$ & œ & $\stackrel{\infty}{\leftarrow}$ & ח & 8 & $\stackrel{\sim}{\sim}$ & $\bullet$ & $\stackrel{\infty}{\sim}$ & $\underset{+}{8}$ \\
\hline $\begin{array}{l}\text { 음 } \\
\text { 음 } \\
0\end{array}$ & $\frac{\frac{n}{1}}{\frac{n}{2}}$ & 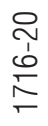 & 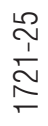 & $\begin{array}{l}\text { 尺 } \\
\text { } \\
\stackrel{N}{=} \\
\end{array}$ & $\begin{array}{l}\stackrel{n}{1} \\
\frac{1}{n} \\
\end{array}$ & 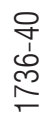 & 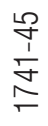 & 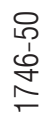 & 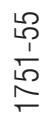 & $\begin{array}{l}0 \\
0 \\
1 \\
0 \\
م \\
\end{array}$ & 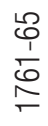 & $\begin{array}{l}0 \\
\stackrel{1}{1} \\
0 \\
1 \\
=\end{array}$ & 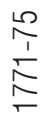 & 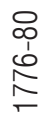 & 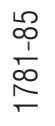 & 覀 \\
\hline
\end{tabular}

Fonte: Instituto dos Arquivos Nacionais/ Torre do Tombo (IANTT). Inquisição de Lisboa (IL), Livro de Registro de Provisões, p.110-123.

11 Devido ao grande número de dados e ao pouco tempo para a pesquisa na Torre do Tombo, não tivemos condições de realizar um levantamento que abrangesse todo o recorte cronológico da pesquisa, 1711-1808. Trata-se, então, de uma amostragem que permite situar a formação da rede de familiares de Minas no contexto maior da América portuguesa. Quanto às familiaturas expedidas para a capitania mineradora, o levantamento corresponde exatamente às balizas cronológicas de 1711-1808. 
Ao observar-se o Quadro 3 e Gráfico 3, constata-se que, até o primeiro quartel do século XVIII, as capitanias do Rio de Janeiro e da Bahia se destacaram pelo maior número de habilitações. No segundo quartel, assisti-se ao emergir da capitania das Minas Gerais, que ultrapassa a da Bahia, e chega ao meio do século XVIII como a região para onde, até então, mais foram expedidas cartas de familiar do Santo Ofício na América portuguesa. No intervalo que se estende do quinquênio de 1741-1745 ao de 1756-1760, Minas Gerais e Rio de Janeiro são as áreas coloniais com maior número de familiaturas, fenômeno indubitavelmente ligado ao dinamismo provocado pela economia do ouro das Gerais.

Durante três qüinqüênios consecutivos, 1746-1750, 1751-1755 e 17561760, Minas se sobressai na colônia pela supremacia de familiaturas expedidas. De maneira geral, o período compreendido entre as décadas de 1740 e 1770 foi o que mais teve familiares habilitados na capitania mineradora. Neste intervalo, formou-se mais da metade da sua rede de agentes inquisitoriais, tendo ocorrido o ápice das habilitações no decênio de 1750.

Ao comparar o ritmo de expedição de familiaturas para Minas Gerais, de modo específico, e para o Brasil, de modo geral, notamos que a curva da capitania acompanha a tendência ascendente da colônia até meados do século XVIII. Depois de 1756-1760, a capitania não consegue mais acompanhar o ritmo geral da América portuguesa.

O pico de Minas foi atingido no quinqüênio 1751-1755, tendo sido expedidas 241 familiaturas para o Brasil e 82 para a capitania, respectivamente. Enquanto o ápice da curva para a colônia ocorreu em 1766-1770, com 250 habilitações, na contracorrente, o número de familiaturas para Minas, neste mesmo período, caiu para 44, quase a metade em relação ao momento anterior que correspondera ao seu auge.

Com exceção do quinquênio 1766-1770, no qual a Capitania apresenta um ligeiro aumento do número de habilitandos, a curva de familiaturas de Minas Gerais é a partir desse momento de queda irreversível. Este movimento corresponde à decadência da mineração, que exerceu impacto direta na vida urbana de Minas Gerais, sobretudo na comarca de Vila Rica, onde a familiatura era mais difundida, conforme veremos. A situação da capitania mineradora fica dramática a partir de 1776-1780, quando as capitanias da Bahia, do Rio de Janeiro e de Pernambuco apresentam uma forte recuperação no número de familiaturas expedidas, o mesmo não ocorrendo com Minas Gerais (Gráfico 4). 
Gráfico 04: Formação da rede de familiares em Minas Gerais, século XVIII

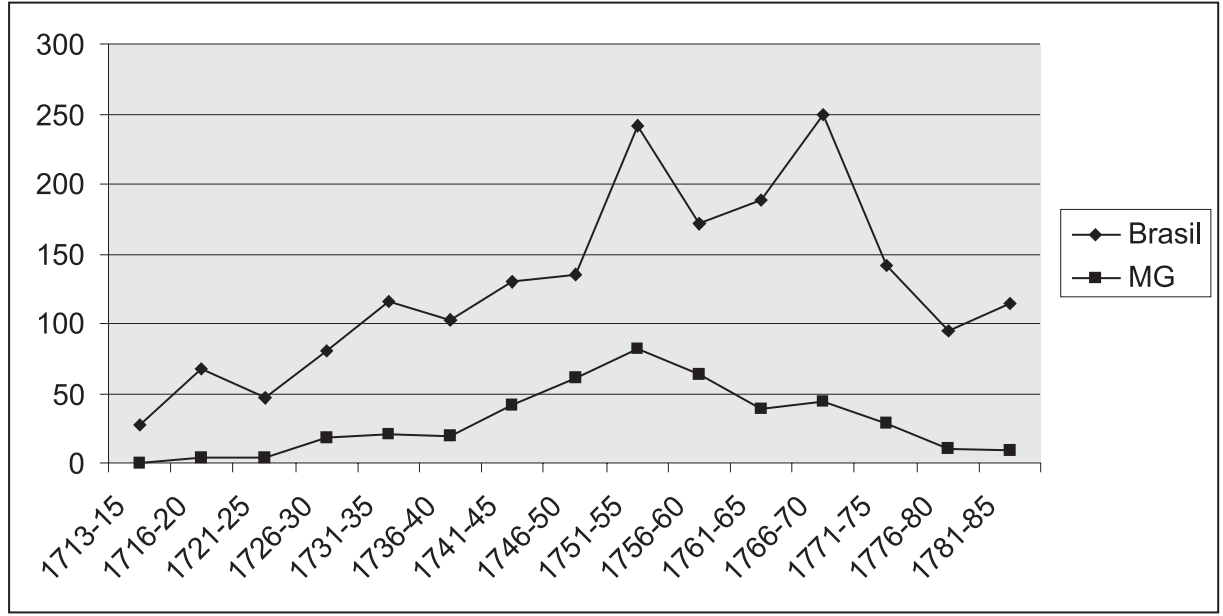

Fonte: IANTT. IL, Livro de Registro de Provisões, liv.110-123.

A expedição de familiaturas para Minas acompanhou o processo de sedimentação da sociedade que ali se formou abruptamente, a partir da corrida do ouro. ${ }^{12}$ Internamente, este é o fator que mais exerceu influência na busca pelo título de familiar do Santo Ofício na capitania. Tal processo de assentamento da sociedade na região ganhou intensidade a partir da década de 1740 e ficou patente na curva da formação da rede de familiares locais.

Isto fica mais claro quando consideramos o perfil sociológico das quase 5 centenas (457) de habitantes das Minas que se habilitaram como familiar. Dentro dos limites deste artigo não é possível expor em detalhes o perfil sociológico dos familiares da capitania (e aqui o objetivo do texto não é este). ${ }^{13}$ De forma resumida, podemos dizer que nessa região, a familiatura foi procurada por um grupo de reinóis, vindos sobretudo do norte de Portugal (principalmente do Minho), homens que saíam muito jovens de suas terras natais em busca da mobilidade social ascendente. A maioria deles era filho de lavradores. Chegando à colônia, se envolviam sobretudo com o comércio que abastecia Minas a partir do Rio de Janeiro, atuando principalmente no setor de comércio de fazendas secas e escravos, sendo comum

12 Do ponto de vista da configuração demográfica da Colônia, em consequência da descoberta do ouro, formou-se um intenso fluxo migratório em direção às Minas. Uma parte dos imigrantes era proveniente das capitanias mais velhas da América portuguesa, como Bahia, Pernambuco e Rio de Janeiro; uma outra corrente vinha de Portugal, sobretudo da região norte. O povoamento das Minas ocorreu de forma tão rápida que Antonil, em 1711, estimava a população já em 30 mil almas. O jesuíta informa que "das cidades, vilas, recôncavos e sertões do Brasil vão brancos, pardos e pretos, e muitos índios de que os paulistas se servem". A mistura, continua Antonil, "é de toda a condição de pessoas: homens e mulheres; moços e velhos; pobres e ricos; nobres e plebeus; seculares, clérigos e religiosos de diversos institutos, muitos dos quais não tem, no Brasil, convento nem casa". ANDREONI, João Antônio (Antonil). Cultura e opulência do Brasil por suas drogas e minas. São Paulo: Editora Nacional, 1967, p.264.

13 Uma análise detida do recrutamento desses agentes, através do método prosopográfico, pode ser encontrada em: RODRIGUES, Aldair Carlos. Sociedade e Inquisição em Minas colonial: os familiares do Santo Ofício, p.142-180. 
mais tarde diversificarem suas atividades econômicas. Abandonando ou não a atividade mercantil, o destino principal dos seus investimentos era a mineração e a aquisição de escravos. No momento em que se tornavam familiares, eram quase todos solteiros e pouquíssimos se casaram depois disso. Isto não significa que permanecessem castos, pois muitos tiveram filhos naturais, na maioria das vezes a partir de relacionamentos com escravas e forras. A maioria dos que conseguia a habilitação tinha entre 30 e 40 anos. Em média, a requisitavam ao Santo Ofício quando já decorrera entre 10 a 20 anos desde sua chegada a Minas. Era esse, em média, o tempo que levavam para ascenderem economicamente e esta ascensão econômica os impulsionava a um movimento de busca por distinção e prestígio social. Essa vontade de distinção social, já trazida pelos membros do grupo desde sua terra natal, então se concretizava no contexto da sociedade escravista colonial que lhes permitira a escalada econômica. ${ }^{14}$ Era nesse movimento que a familiatura passava a fazer parte da trajetória desse grupo em processo de mobilidade social ascendente.

Não é possível encetar uma análise comparativa de todos os elementos que caracterizam o perfil social dos familiares que atuaram em Minas com os de outras regiões da colônia, devido à ausência de abordagem similar para outras localidades, principalmente no que diz respeito às questões aqui levantadas, pois os estudos até então disponíveis baseiam-se quase exclusivamente nas cartas de habilitações do Santo Ofício e não têm como proposta analisar a trajetória de vida de cada indivíduo do grupo. No estudo de Wadsworth - o mais detalhado já realizado sobre os familiares e cujo recorte é Pernambuco colonial - observamos que uma parcela significativa dos familiares se habilitou antes de completar 25 anos. Em Minas, o número de pessoas que se habilitou nessa mesma faixa etária era ínfimo. Muitos dos familiares de Pernambuco eram filhos ou netos de pessoas já habilitadas no Santo Ofício. Na capitania mineradora, de assentamento recente, isto praticamente não acontecia. Quanto à naturalidade, em Minas, a quase totalidade dos familiares era composta de reinóis, diferentemente de Pernambuco, onde, apesar de uma parcela significativa deles ser natural do reino, expressivos 44,2\% eram nascidos na colônia. Embora não fosse gritante como em Minas, em Pernambuco também a maior parte $(55,1 \%)$ dos familiares foi recrutada no setor mercantil. ${ }^{15}$ Quanto à colônia de maneira mais ampla, o levantamento que Calainho realizou nos catálogos das habilitações do Santo Ofício (que vai até os nomes iniciados pela letra $\mathrm{J}$ ) indica algumas tendências gerais sobre o perfil dos familiares

14 SCHWARTZ, Stuart. Segredos internos: engenhos, e escravos na sociedade colonial (1550-1835). São Paulo: Companhia das Letras, 1988. Sobretudo o capítulo 9.

15 WADSWORTH, James. Agentes of orthodoxy, p.176-193. Assim como os demais trabalhos sobre as familiaturas, o autor não utiliza fontes, tais como inventários e testamentos, que fornecem dados sobre a vida dos familiares após o momento que eles se habilitam. 
do Brasil habilitados nos séculos XVI, XVII e XVIII. A autora aponta que a maioria deles era nascida em Portugal e atuava no setor mercantil. ${ }^{16}$ Ainda sobre o perfil ocupacional dos familiares, Veiga Torres verificou que, com algumas variações, a predominância de familiares comerciantes ocorreu em todas as áreas sob jurisdição do Santo Ofício português, desde o final do século XVII, e atingiu seu auge em meados do século XVIII. ${ }^{17}$ Apesar de algumas dessas tendências gerais indicadas acima serem para Minas Gerais, principalmente no que diz respeito à ocupação, o perfil sociológico das redes de familiares de cada localidade possui especificidades que espelha a dinâmica da sociedade onde as pessoas interessadas no título estavam inseridas. No caso de Minas, a formação da sua rede de familiares está relacionada, do ponto de vista local, ao processo de assentamento da sociedade mineradora em meados do século XVIII.

Alguns elementos corroboram a nossa hipótese de um processo de assentamento da sociedade das Minas em meados do XVIII, quais sejam: (I) a frequência dos "mineiros" na Universidade de Coimbra, (II) a festa do Áureo Trono Episcopal e (III) o surgimento das Ordens Terceiras de São Francisco e do Carmo. Vejamos:

(I) Os estudantes, que iam estudar na metrópole, eram filhos da "primeira geração de aventureiros que enriqueceu com o ouro, com a agricultura, com o comércio e com a máquina administrativa burocrática". ${ }^{18}$ A matrícula de estudantes procedentes das Minas na universidade coimbrã ganha força a partir de 1740, atinge seu ápice na década de 1750 e começa a entrar em decadência no auge das reformas pombalinas, já no momento da crise da mineração. ${ }^{19}$ Como vimos, a procura pela familiatura do Santo Ofício segue essa mesma tendência de auge em meados do setecentos e de decadência a partir do segundo quartel do século XVIII.

(II) Outra marca do assentamento da sociedade mineradora é a festa do Áureo Trono Episcopal, de 1748, que celebrou a chegada do bispo dom Frei Manuel da Cruz ao recém-criado bispado de Mariana. Laura de Mello e Souza, comparando esta festa com a do Triunfo Eucarístico, de 1733, afirmou que "a ênfase ritual dada à recepção do bispo em 1748 e o certame literário retratam, por sua vez, uma sociedade onde normas e limites já se encontravam mais bem estabelecidos". ${ }^{20}$

16 CALAINHO, Daniela Buono. Em nome do Santo Ofício: familiares da Inquisição portuguesa no Brasil colonial, p.7798. A análise da autora sobre os familiares leva mais em conta as funções institucionais desses agentes, seu foco não é o aspecto social da familiatura, embora este não seja ignorado.

17 TORRES, José Veiga. Da repressão religiosa para a promoção social: a Inquisição como instância legitimadora da promoção social da burguesia mercantil, p.133-134

18 VALADARES, Vírginia Trindade. Elites mineiras: conjugação de dois mundos. Lisboa: Edições Colibri; Instituto de Cultura Ibero-Atlântica, 2004, p.511.

19 VALADARES, Vírginia Trindade. Elites mineiras: conjugação de dois mundos, p.391, 512-513.

20 SOUZA, Laura de Mello e. Festas barrocas e vida cotidiana em Minas Gerais. In: KANTOR, Íris; JANCSÓ, István. (orgs.) Festa: cultura e sociabilidade na América portuguesa. São Paulo: Edusp, FAPESP, Hucitec, 
Temos ainda, como sintoma do processo de sedimentação social, (III) a fundação das ordens terceiras de São Francisco e do Carmo. Se antes, a elite branca estava presente nas irmandades do Rosário, Santíssimo e São Miguel, a partir de meados do século XVIII, ela vai se aglutinar sobretudo nas ordens terceiras, que tinham critérios de admissão muito mais rígidos. ${ }^{21}$

Portanto, vale repetir que, analisando a formação da rede de familiares do Santo Ofício em Minas, notamos que ela se relaciona principalmente ao processo de assentamento da sociedade mineradora, ocorrido a partir de meados do setecentos. Ao reduzirmos a escala de análise, notamos que tal formação por comarca acompanhou o mesmo ritmo geral de expedição de familiaturas para a capitania: para todas as comarcas, o maior número de habilitações ocorreu entre as décadas de 1740 e 1770 (Quadro 4 e Gráfico 5).

Quadro 4: Formação da rede de familiares por período e comarcas

\begin{tabular}{|c|c|c|c|c|c|c|}
\hline Ano & Vila Rica & $\begin{array}{c}\text { Rio das } \\
\text { Velhas }\end{array}$ & $\begin{array}{c}\text { Rio das } \\
\text { Mortes }\end{array}$ & Serro & $\begin{array}{c}\text { Minas (sem } \\
\text { especificação) }\end{array}$ & Total \\
\hline $1716-20$ & 04 & 00 & 00 & 00 & 00 & 04 \\
\hline $1721-25$ & 01 & 02 & 01 & 00 & 00 & 04 \\
\hline $1726-30$ & 14 & 01 & 01 & 00 & 02 & 18 \\
\hline $1731-35$ & 15 & 03 & 01 & 01 & 01 & 21 \\
\hline $1736-40$ & 10 & 03 & 02 & 02 & 03 & 20 \\
\hline $1741-45$ & 30 & 04 & 03 & 01 & 04 & 42 \\
\hline $1746-50$ & 42 & 05 & 08 & 04 & 02 & 61 \\
\hline $1751-55$ & 53 & 10 & 15 & 03 & 01 & 82 \\
\hline $1756-60$ & 32 & 11 & 11 & 04 & 05 & 63 \\
\hline $1761-65$ & 19 & 07 & 08 & 03 & 02 & 39 \\
\hline $1766-70$ & 19 & 06 & 14 & 05 & 00 & 44 \\
\hline $1771-75$ & 10 & 08 & 08 & 02 & 01 & 29 \\
\hline $1776-80$ & 05 & 02 & 03 & 00 & 01 & 11 \\
\hline $1781-85$ & 01 & 00 & 04 & 04 & 00 & 09 \\
\hline $1786-90$ & 00 & 00 & 01 & 00 & 01 & 02 \\
\hline $1791-95$ & 01 & 02 & 00 & 01 & 00 & 04 \\
\hline $1796-00$ & 00 & 00 & 01 & 00 & 00 & 01 \\
\hline $1801-05$ & 00 & 00 & 00 & 00 & 00 & 00 \\
\hline $1806-10$ & 01 & 00 & 00 & 00 & 00 & 01 \\
\hline $\mathrm{n} / \mathrm{c}$ & 02 & 00 & 00 & 00 & 00 & 02 \\
\hline total & 259 & 64 & 81 & 30 & 23 & 457 \\
\hline
\end{tabular}

Fonte: IANTT. IL, Livro de Registro de Provisões, liv.110-123.

Imprensa Oficial, 2001, v.1, p.188

21 SOUZA, Laura de Mello e. O sol e a sombra: política e administração na América portuguesa do século XVIII. São Paulo: Companhia das Letras, 2006, p.174; FURTADO, Júnia. Homens de negócio: a interiorização da metrópole e o comércio nas Minas Setecentistas. São Paulo: Hucitec, 1999, p.136-142; Cf. também: BOSCHI, Caio César. Os leigos e o poder: irmandades leigas e política colonizadora em Minas Gerais. São Paulo: Ática, 1986; SALLES, Fritz Teixeira. Associações religiosas no ciclo do ouro. Belo Horizonte: UFMG, Centro de Estudos Mineiros, 1963. (Coleção Estudos, 1); 
Gráfico 5: da Formação da rede de familiares de Minas por comarca e período

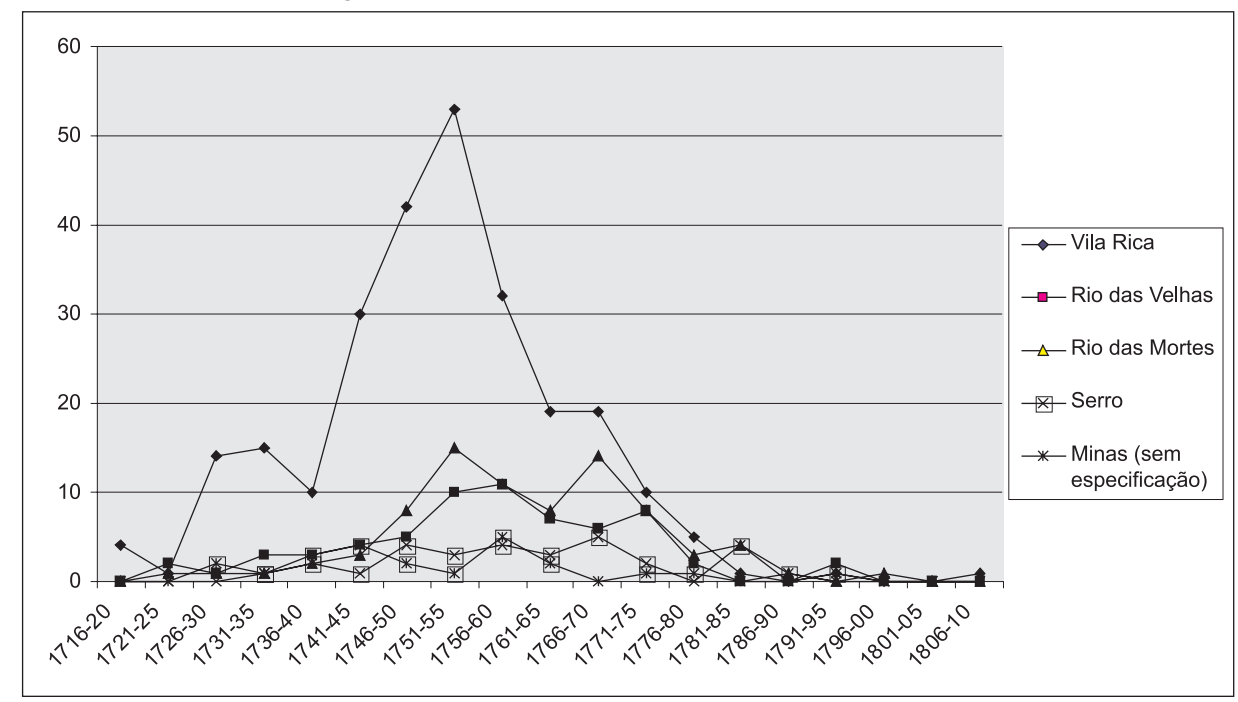

Fonte: IANTT. IL, Livro de Registro de Provisões, liv.110-123.

Quanto ao número de habilitações por comarca, observamos um predomínio absoluto da de Vila Rica. Ao longo do século XVIII, mais da metade dos familiares da capitania moravam em freguesias dos seus dois termos, com uma ligeira predominância do termo de Vila Rica sobre o de Mariana. No auge da expedição de cartas de familiar do Santo Ofício para Minas, a Inquisição chegou a habilitar, por exemplo, no quinqüênio 1751-1755, 53 familiares para a comarca de Vila Rica. Para se ter uma ideia desta concentração, basta notar que a comarca do Serro Frio, ao longo de todo o século XVIII, teve apenas 30 familiares.

A comarca de Vila Rica era composta por duas importantes vilas, com seus respectivos termos: Vila Rica e Mariana. A população dessa comarca foi a que mais vivenciou a euforia propiciada pela mineração, investindo muito no luxo e na ostentação. Isto fica patente, por exemplo, no fato de que as duas mais importantes festas barrocas do setecentos mineiro ocorreram na referida comarca: o Triunfo Eucarístico, em Vila Rica, de 1733, cujo evento trasladou o Santíssimo da Igreja do Rosário para a nova Matriz do Pilar, e o Áureo Trono Episcopal, de 1748 que celebrou a entrada de Dom Frei Manuel da Cruz na cidade de Mariana. ${ }^{22}$

22 Sobre as festas barrocas do setecentos mineiro, ver SOUZA, Laura de Mello e. Desclassificados do ouro: a pobreza mineira no século XVIII. $4^{a}$ edição revista e ampliada. São Paulo: Paz e Terra, 2004, p.33-75. KANTOR, Iris. Entradas episcopais na capitania de Minas Gerais (1743-1748): a transgressão formalizada. In: KANTOR, Íris; JANCSÓ, István. (orgs.) Festa, v.1, p.169-182; ÁVILA, Afonso. (org.) Resíduos seiscentistas em Minas: textos do século do ouro e as projeções do mundo barroco. Belo Horizonte, 1967. 
A primeira hipótese que levantamos para explicar a concentração das familiaturas na comarca de Vila Rica está relacionada ao dinamismo que essa região alcançou em decorrência da mineração. Dinamismo este muito bem observado pelo autor do Triunfo Eucarístico, que descreve que,

nesta vila [Rica] habitam os homens de maior comércio, cujo tráfego e importância excede sem comparação o maior dos maiores de Portugal: a ela, como a porto, se encaminham, e recolhem as grandiosas somas de ouro de todas as Minas na Real Casa da Moeda: nela residem os homens de maiores letras, seculares, e eclesiásticos: nela tem assento toda a nobreza, e força da milícia; é por situação da natureza cabeça de toda a América, pela opulência das riquezas a pérola preciosa do Brasil. ${ }^{23}$

Em 1766, segundo levantamentos de Carla Almeida, 45,2\% das lavras de Minas Gerais se concentravam na Comarca de Vila Rica, seguida pela do Rio das Velhas (27,8\%), Rio das Mortes (18\%), e Serro Frio, que detinha apenas 9\% das lavras de Minas Gerais. ${ }^{24}$

Outra hipótese que explica o fato de a população da comarca de Vila Rica ter sido a que mais procurou a familiatura do Santo Ofício é que aquela comarca era a cabeça civil da Capitania. Após a revolta de 1720, ${ }^{25}$ a Coroa criou a capitania das Minas Gerais, que passou, então, a ficar administrativamente independente de São Paulo. A sede do governo da nova capitania ficou sendo Vila Rica e, conseqüentemente, as autoridades e as instituições metropolitanas, baluartes dos valores de distinção social do Antigo Regime nas Minas, concentravam-se em sua comarca.

Por conviver mais intensamente com os valores metropolitanos de distinção e organização social trazidos pelas autoridades da Coroa, a população da cabeça civil da capitania tendia a valorizar e a ambicionar mais as insígnias e símbolos de status e distinção social - dentre eles, a carta de familiar do Santo Ofício -, se comparada aos habitantes das demais comarcas de Minas.

Sob os valores de Antigo Regime, as insígnias e símbolos de distinção social cumpriam importante papel na demarcação das hierarquias sociais. No que diz respeito à pratica do mando, havia uma cultura política em que "os membros das famílias mais antigas, nobres e ricas eram os que davam maiores garantias de isenção e independência no desempenho dos

23 ÁVILA, Affonso. Resíduos seiscentistas em Minas.

24 ALMEIDA, Carla. Homens ricos, homens bons: produção e hierarquização social em Minas colonial: 1750-1822. Niterói: UFF, 2001, p.62-63. (História, Tese de doutorado).

25 Sobre a Revolta de 1720 e a reação do poder metropolitano e seu impacto, ver SOUZA, Laura de Mello e. Norma e conflito: aspectos da história de Minas no século XVIII. Belo Horizonte, Editora da UFMG, 1999, p.30-42; SOUZA, Laura de Mello e. Desclassificados do ouro, p.131-201; CAMPOS, Maria Verônica. Governo de mineiros: "de como meter as Minas numa moenda e beber-lhe o caldo dourado" (1693-1737). São Paulo: FFLCH-USP, 2002, p.230-260. (História, Tese de doutorado). 
seus ofícios e os que dispunham de uma autoridade natural, no sentido de construída pelo tempo, e, por isso, mais facilmente acatada" ${ }^{26}$

Nessa perspectiva, analisando o recrutamento dos governadores da capitania mineradora, Laura de Mello e Souza verificou que a linhagem, além de ter sido um dos principais critérios para a escolha dos mesmos, tinha importância simbólica. Em suas palavras, "no meio rude das Minas, onde a sociedade se achava em processo de sedimentação, assumia, inclusive, função pedagógica, obrigando ao respeito devido aos grandes nobres e então tido por natural". ${ }^{27}$

É possível encontrar a familiatura do Santo Ofício entre as distinções e insígnias típicas do Antigo Regime português, que eram ostentadas pelas autoridades das Minas. No caso dos governadores, por exemplo, encontramos, pelo menos, dois deles que eram familiares do Santo Ofício: dom Lourenço de Almeida e Luis Diogo Lobo da Silva. Dom Lourenço veio para as Minas já habilitado, sendo que seu processo teve desfecho favorável em 1696, "em ocasião de passar à Índia". 28 O segundo,"sem dúvida um dos mais importantes governadores que as Minas tiveram", se tornou familiar em 1739, quando contava 20 anos de idade. Como o primeiro, era também Cavaleiro da Ordem de Cristo, tendo se habilitado em 1742. ${ }^{29}$

Não temos notícias da atuação de Luís Diogo enquanto agente da Inquisição, mas no que se refere a Dom Lourenço de Almeida, sabemos que ele era um familiar do Santo Ofício atuante. Como exemplo, há uma carta escrita por ele ao comissário do Rio de Janeiro, Lourenço de Valadares Vieira, em 1730:

Recebi sete mandados do Santo Ofício conforme a lista que V. M. me remeteu deles e eu agradeço muito a V. M. a mercê que me faz de me dar ocasião de servir ao Santo Tribunal de quem há muitos anos sou familiar, e como tenho grande gosto de o servir e grande honra, tenho ajudado nestas Minas a muitos familiares para fazerem varias prisões de réus que se remeterão. ${ }^{30}$

Nesta carta, dom Lourenço dava conta ainda da prisão de Diogo Correa do Vale e de seu filho, Luis Miguel, ambos moradores na Comarca de Vila Rica.

A familiatura como uma forma de distinção social, sobretudo porque correspondia a um atestado público de limpeza de sangue, ${ }^{31}$ era comumente encontrada entre os grandes de Portugal. Basta lembrar, por exemplo, de

26 MONTEIRO, Nuno Gonçalo. Elites e poder: entre o Antigo Regime e o Liberalismo. Lisboa: Imprensa de Ciências Sociais, 2003, p.44.

27 SOUZA, Laura de Mello e. Norma e Conflito, p.193.

28 IANTT. HSO, maço 01, doc. 35.

29 SOUZA, Laura de Mello e. Norma e Conflito, p.187.

30 IANTT. IL, proc. 821.

31 Ver RODRIGUES, Aldair Carlos. Sociedade e Inquisição, capítulo 3. 
dom Luis da Cunha ${ }^{32}$ e do marquês de Pombal, ${ }^{33}$ bem como outros membros de suas respectivas famílias. Além do título de familiar, em si, já oferecer distinção social, o fato de dom Lourenço atuar em prisões do Santo Ofício, certamente, causava um impacto entre a população da cabeça civil das Minas no sentido de acrescentar prestígio ao cargo de familiar do Santo Ofício.

A expedição das familiaturas para Minas até meados do século XVIII acompanhou o desenvolvimento da mineração e o dinamismo que ela provocava na economia das Minas. Isso se refletiu na formação da rede de familiares da comarca de Vila Rica, principal região mineradora da capitania. No entanto, na comarca do Rio das Mortes, onde ocorreu um extraordinário desenvolvimento da agropecuária, assistimos a um descolamento dos dois processos, isto é, entre o dinamismo econômico-social e o incremento do ritmo de expedição de familiaturas.

Após a década de 1760, começaram a ocorrer profundas alterações na economia das Minas: a mineração paulatinamente foi perdendo o papel dominante que ocupara até então e a agropecuária passou a se destacar como a mais dinâmica das atividades econômicas da Capitania. É importante dizer que essa "mudança era gradual e a transformação de uma economia predominantemente mineira em uma de supremacia agrícola não significava que qualquer uma delas, a primeira ou a última, jamais tivesse sido excludente em relação à outra". ${ }^{34}$

A atividade mineradora era mais difundida na região central das Gerais, sobretudo na comarca de Vila Rica, e a agropecuária era mais praticada na porção sul da capitania, nomeadamente na comarca do Rio das Mortes. Com efeito, o peso que cada uma dessas comarcas tinha dentro das Minas foi se alterando na medida em que o eixo econômico principal da capitania era deslocado da mineração para a agropecuária. ${ }^{35}$ Por exemplo, entre 1749 e 1767, a comarca do Rio das Mortes apresentou um aumento da sua população escrava em torno de 96\%, a do Rio das Velhas em 52\%, "enquanto que a de Vila Rica sofreu uma queda de 1,6\%". ${ }^{36}$

32 Ver CUNHA, Dom Luís da. Instruções Políticas. Lisboa: Comissão Nacional para as Comemorações dos Descobrimentos Portugueses, 2001. (Introdução, estudo e edição crítica de Abílio Diniz Silva).

33 SENA, Maria Teresa. A família do marquês de Pombal e o Santo Ofício. In: SANTOS, Maria Helena Carvalho dos Santos. (org.) Pombal revisitado. Lisboa: Imprensa Universitária; Editorial Estampa, 1984, v.1, p.337-386.

34 MAXWELL, Keneth. A devassa da devassa: a Inconfidência Mineira, Brasil-Portugal, 1750-1808; tradução de João Maia. $2^{a}$ ed. Rio de Janeiro: Paz e Terra, 1978, p.110.

35 Carla Almeida afirma que "pelo menos até o final da década de 1760, era Vila Rica a comarca de maior importância para a Coroa portuguesa dentro da capitania, garantindo a Minas Gerais a caracterização de região primordialmente aurífera e a menina dos olhos da administração colonial, ainda que já se delineasse uma mudança de eixo da economia". ALMEIDA, Carla. Homens ricos, homens bons: produção e hierarquização social em Minas colonial, p.71. Sobre a mudança do eixo central da economia de Minas Gerais em finais do século XVIII, sobretudo no que diz respeito às atividades mercantis, ver LENHARO, Alcir. As tropas da moderação: o abastecimento da Corte na formação política do Brasil (1808-1842). São Paulo: Símbolo, 1979.

36 ALMEIDA, Carla. Homens ricos, homens bons, p.50-51. 
Quanto à distribuição da população, de modo geral, Maxwell, baseado em dados de 1776 e de 1821, verificou que a "comarca de Vila Rica, nas quatro décadas seguintes ao censo de 1776, apresentou um declínio demográfico. Rio das Mortes, entretanto, no mesmo período quase triplicou sua população: de 82.781 , em 1776, para 213.617, em 1821". ${ }^{37}$

Esperávamos que, a partir da segunda metade do século XVIII, o maior peso que a região do Rio das Mortes, paulatinamente, passou a ocupar no equilíbrio econômico interno de Minas Gerais acabasse se refletindo na curva de expedição de familiaturas para sua comarca. No entanto, a procura pela familiatura no Rio das Mortes - 81 familiares habilitados no total - não foi tão alta, como ocorrera na região de Vila Rica no momento de seu apogeu - 259 agentes habilitados durante todo o setecentos. Por quê? Uma hipótese que pode explicar o menor interesse da população da comarca do Rio das Mortes em relação à familiatura é a de que, a partir da década de 1770, momento em que a comarca passa a ganhar destaque na capitania, há uma diminuição generalizada da procura da carta de familiar do Santo Ofício, em decorrência da abolição da distinção entre cristãosvelhos e cristãos-novos e à decadência da Inquisição nas últimas décadas do século XVIII sob os ventos da llustração. ${ }^{38}$

Outra hipótese - complementar à anterior - que pode explicar o pouco interesse dos habitantes do Rio das Mortes pelo título de familiar do Santo Ofício no momento em que essa comarca passa a ser o centro econômico e social mais dinâmico das Minas é o caráter mais rural de sua população. Queremos sugerir que a baixa procura dos habitantes do Rio das Mortes pela familiatura se explica, dentre outros fatores, pelo fato de que o título de familiar do Santo Ofício tinha maior difusão na área mais urbanizada das Minas, e esta era aquela ligada sobretudo à mineração. ${ }^{39}$

A população do sul de Minas, envolvida principalmente com as atividades econômicas agropecuárias, era, se comparada à da comarca de Vila Rica, mais rústica, ou seja, menos afeita à ostentação e ao luxo. Na comarca de Vila Rica, mesmo com a crise da mineração, seus habitantes continuavam valorizando e investindo em "objetos que garantissem o seu bom tratamento". ${ }^{40}$

Comparando a presença dos apetrechos de uso pessoal, mobília e utensílios domésticos entre os inventários da comarca de Vila Rica e do Rio das Mortes, Carla Almeida verificou que "talheres de prata, louças da índia, móveis de jacarandá torneados, vestimentas e colchas de damas-

37 MAXWELL, Keneth. A Devassa da devassa, p.110

38 Sobre esta questão, ver: RODRIGUES, Aldair Carlos. Sociedade e Inquisição em Minas colonial, capítulo 3.

39 Segundo Laura de Mello e Souza, apesar da urbanização em Minas ter correspondido "a uma política deliberada do Estado, é preciso não esquecer que a atividade mineradora, pelo seu próprio caráter, propicia a formação de núcleos urbanos". SOUZA, Laura de Mello e. Desclassificados do Ouro, p.152. nota 38.

40 ALMEIDA, Carla. Homens Ricos, Homens Bons, p.185-186. 
co, chamalote ou linho" eram muito mais abundantes entre os inventários referentes à primeira comarca, tanto no período que vai de 1750 a 1779, como no período compreendido entre os anos 1780 e $1822 .{ }^{41}$ Na região do Rio das Mortes, "se entre 1750 e 1779 a descrição deste tipo de bem não era incomum, no período de 1780 a 1822, se tornou cada vez mais rara". A constatação de que os habitantes do Rio das Mortes eram menos ligados à ostentação se verifica também no percentual que as jóias ocupavam no monte-mor: nos inventários de Vila Rica, este item quase não sofre alteração do primeiro para o segundo período considerado pela autora, ou seja, de 1750-1779 para 1780-1822; já na comarca do Rio das Mortes, mesmo no seu período de maior pujança econômica, o percentual que as jóias ocupavam nas fortunas inventariadas - que já era menor que o peso que este mesmo item ocupava em Vila Rica - diminui do primeiro para o segundo período.

Por um lado, Saint-Hilaire observou na comarca do Rio das Mortes, no início do novecentos, "menos conhecimentos, menos polidez e mesmo menos hospitalidade, que nas outras partes da província". ${ }^{42}$ Por outro lado, John Mawe, quando passou por Vila Rica, no início do século XIX, se impressionou com a sofisticação que via: "as casas das classes mais abastadas em Vila Rica estão melhor arranjadas e mobiliadas do que as que vi no Rio de Janeiro e em São Paulo". ${ }^{43}$

Ao que tudo indica, em virtude da comarca do Rio das Mortes ser habitada por uma população mais "rústica", portanto, menos afeita à ostentação, e por esta comarca ter atingido o seu dinamismo econômico e social quando a Inquisição já estava decadente, seus habitantes - se comparados aos de Vila Rica no momento áureo da mineração - não apresentaram tanto interesse pelo título de familiar do Santo Ofício.

\section{Considerações finais}

Existem várias possibilidades de enquadramento analítico para se compreender uma instituição do porte da Inquisição portuguesa cuja atuação beirou três séculos. Predomina na historiografia abordagens que levam em conta a atividade repressiva do Santo Ofício. Neste artigo procuramos compreender a formação da rede de familiares da região mineradora a partir de uma análise que privilegia o aspecto social dessa problemática. Adotando essa perspectiva, verificamos que em Minas a familiatura teve maior difusão no espaço urbanizado e relacionado à mineração, justamente onde

41 Para analisar as alterações nas unidades produtivas da capitania das Minas a autora estabelece dois períodos para fins comparativos: o primeiro, de 1750 a 1779, e o segundo, de 1780 a 1822. ALMEIDA, Carla. Homens Ricos, Homens Bons, p.186.

42 SAINT-HILAIRE, Auguste de. Viagem pelo Distrito dos Diamantes e Litoral do Brasil. Belo Horizonte/São Paulo: Edusp/Itatiaia, 1974, p.107.

43 MAWE, John. Viagens ao Interior do Brasil. Belo Horizonte/São Paulo: Edusp/Itatiaia, 1978, p.141. 
a ostentação era mais valorizada. Ao mesmo tempo, a difusão da insígnia esteve ligada à prosperidade econômica da zona mineradora central, responsável pela mobilidade social ascendente de centenas de reinóis. Ainda no que diz respeito ao contexto interno da capitania, a formação da rede de familiares relacionou-se à consolidação do poder metropolitano na região e ao assentamento da sociedade formada abruptamente a partir da corrida do ouro. Externamente, a formação da rede esteve ligada à expansão geral da expedição de habilitações pelo Santo Ofício que atinge seu ápice em meados do século XVIII.

O percurso analítico deste trabalho evidencia que a Inquisição era uma instituição dinâmica e permeável à configuração social dos espaços por onde atuava. No caso de Minas setecentista, apresentamos e discutimos como o contexto local da capitania influenciou na formação da rede de familiares do Santo Ofício que atuou na região. Isto foi possível através da análise do comportamento da curva de expedição de familiaturas para as quatro comarcas da capitania ao longo do século XVIII. 